\title{
Certification of deaths attributable to epilepsy
}

\author{
Y Langan, L Nashef, J W A S Sander
}

J Neurol Neurosurg Psychiatry 2002;73:751-752

Objective: To estimate the number of sudden unexpected epilepsy deaths occurring annually in England and Wales in those 16-50 years of age.

Methods: All 1997 death entries mentioning epilepsy as a cause of death in those 16-50 years were examined and classified as sudden unexpected death in epilepsy (SUDEP), other epilepsy related deaths, or non-epilepsy deaths.

Results: 612 death entries were obtained with postmortem examination having been performed in 498 cases. Forty four deaths were certified as being attributable to SUDEP and a further 292 deaths were considered to be probable SUDEP cases.

Conclusion: It is estimated that between 350 and 400 cases of SUDEP occurred in England and Wales in 1997 in those 16-50 years. SUDEP is the commonest category of epilepsy related death and accurate certification of such deaths is vital for the monitoring of trends in mortality.

$\mathrm{S}$ udden unexpected death is responsible for some of the increased mortality seen in the population with epilepsy, its incidence varying from $1: 100$ to $1: 1000$ depending on the population studied. ${ }^{1-3}$ The lowest incidence of $1: 2900$ was reported from a population based incidence study, but the number of cases classified as sudden unexpected death in epilepsy ( SUDEP) was small (definite and probable $=9$ ) and there were six cases with insufficient data to classify death. ${ }^{4}$ Lack of consistency in death certification results in national statistics that are difficult to interpret. ${ }^{5}$ We have been made aware of a large number of SUDEP cases as part of an ongoing case-control study. Postmortem reports and inquest proceedings relating to these cases have been received and this has allowed us to gain considerable experience in the interpretation of death certificates as issued in England and Wales during this decade. In the UK $90 \%$ of such deaths will be referred to the coroner and undergo postmortem examination. ${ }^{6}$ Estimates of the number of SUDEP cases occurring have ranged from 250 to 1400 per annum but have not been based on any data.

Our aim was to determine the number of epilepsy related deaths, in particular, the number of sudden and unexpected deaths in those aged 16-50 years for the year 1997 by careful examination, interpretation, and corroboration of death certificates mentioning epilepsy as a possible cause of death.

\section{METHODS}

All death entries for England and Wales mentioning epilepsy in those 16-50 years for the year 1997 were received from the Office for National Statistics.

For the purposes of our research we define SUDEP as sudden, unexpected, witnessed or unwitnessed, non-traumatic and non-drowning death in an individual with epilepsy with or without evidence for a seizure and excluding documented status epilepticus where postmortem examination does not reveal a cause for death. ${ }^{8}$
Death certificates were examined and deaths classified as likely SUDEP, other epilepsy related deaths, or non-epilepsy deaths. Possible SUDEP deaths were considered to be those where death was certified as any of the following: (la) sudden unexpected death in epilepsy, (la) epilepsy/epileptic fit, (la) asphyxia, hypoxia, cardiorespiratory arrest, or pulmonary oedema and ( $\mathrm{lb}$ ) epilepsy/epileptic fit. To confirm the accuracy of our death certificate interpretation 50 death entries were chosen at random from the total number received and where applicable postmortem reports and inquest proceedings were sought from the appropriate coroners' office. Furthermore, because of concern relating to the inaccuracy of certification of deaths as attributable to status epilepticus, with previous reports of SUDEP cases being certified as attributable to status, ${ }^{2}$ all certificates with status epilepticus as the cause of death were identified and where applicable postmortem reports and inquest proceedings requested.

Ethical committee approval was obtained from the Joint Ethics Committee of the National Hospital for Neurology and Neurosurgery and University College Hospital, London.

\section{RESULTS}

Altogether 612 death entries were received relating to 397 men and 215 women with a median age of 35 years.

Only death certificates relating to those ages 16 to 50 years were requested. A total of 498 (81\%) people had undergone postmortem examination. Forty four death entries stated that the cause of death was sudden unexpected death in epilepsy and a further 292 deaths were considered probable SUDEP. Sixty nine deaths were certified as being attributable to status epilepticus. There were a further 71 epilepsy related deaths with 136 deaths deemed unrelated to epilepsy.

Of the 50 death entries chosen at random 38 people had undergone postmortem examination. Thirty five postmortem reports were received from coroners and details are shown in table 1.

Of the 69 deaths certified attributable to status epilepticus $40(58 \%)$ had undergone postmortem examination and necropsy reports were obtained in 23 of these cases. In 19 $(83 \%)$ of these cases the coroner's officers' and postmortem reports indicated that there was no evidence of documented status epilepticus and that the case would be more appropriately classified as SUDEP. Taking into consideration the observation that sudden unexpected deaths, including SUDEP cases, often undergo necropsy in the UK, these figures suggest that nearly half of cases certified as status epilepticus are more appropriately classified as SUDEP. In three of the remaining four cases evidence supported a classification of status epilepticus and in one further case although there was no documented status epilepticus the person concerned had a congenital heart defect and death could not be reliably reclassified as SUDEP.

\section{DISCUSSION}

Thus, if we consider the rare false positive rate ( 1 of 35 or $2.9 \%$ among the random subgroup) among the 336 cases we classified as SUDEP, and the significant false negative rate among 


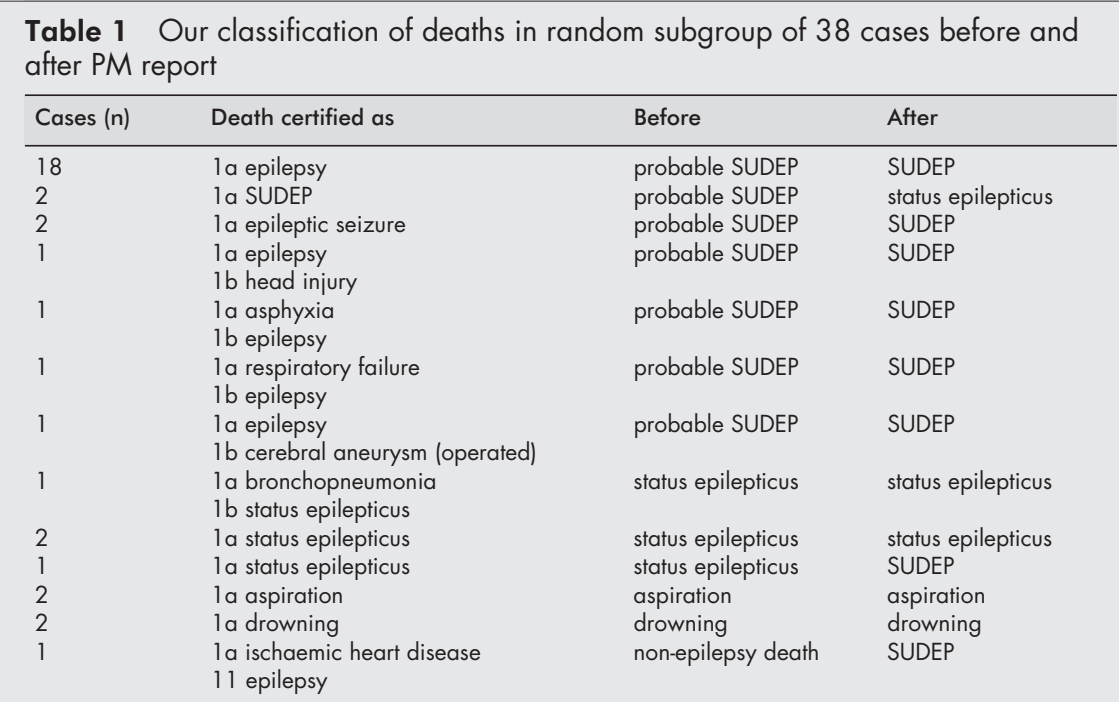

other cases particularly the 69 status certified cases, we conclude that about 360 SUDEP cases occurred in England and Wales in 1997 in those 16-50 years. This confirms that SUDEP is the commonest category of epilepsy related death. We did not request death certificates on those who, in England and Wales in 1997, died less than 16 or greater than 50 years of age, there were 69 deaths in the age group 0-19 years certified as being attributable to epilepsy and 285 among those aged greater than 50 in England and Wales during 1997. ${ }^{9}$ It is possible that deaths attributable to epilepsy were not certified as such and therefore not included in this study.

For the most part, we interpreted death entries correctly, with the postmortem report only changing our classification in three of the 35 cases classified as SUDEP where such reports were received. The certification of cause of death as attributable to status epilepticus remains problematic, with false positive and less frequent false negative certificates. We would suggest that deaths only be certified as being attributable to status epilepticus if there is a documented history of uncontrolled fitting. A high proportion of deaths that are attributed to status epilepticus are SUDEP cases, especially where such deaths have been referred to the coroner. The mid-2000 population of England and Wales in the 16-50 age group was 25.64 million. ${ }^{9}$ The prevalence of epilepsy is $0.5 \%-$ $1 \%^{10}$ and as there were about 360 sudden epilepsy deaths in this age group the incidence of SUDEP is therefore 1:356 to 1:712 comparable to the rates found in other studies. ${ }^{1-4}$ While this provides a population based estimate of the incidence of SUDEP, it only applies to the age groups studied, which are generally considered of higher risk.

Correct certification of epilepsy deaths is vital both for accurate data on SUDEP and other epilepsy related deaths and to allow for the monitoring of trends in mortality.

\section{Authors' affiliations}

Y Langan, J W A S Sander, Epilepsy Research Group, Institute of Neurology, London, UK

L Nashef, Department of Neuroscience, Kings College Hospital, London and Kent and Canterbury Hospital, Canterbury, UK

Competing interests: none declared.

Correpondence to: Dr Y Langan, Department of Neurology, Royal Victoria Infirmary, Queen Victoria Road, Newcastle NE 1 4LP, UK; canavan@ukgateway.net

Received 3 September 2001

In revised form 14 May 2002

Accepted 16 May 2002

\section{REFERENCES}

1 Nashef L, Fish DR, Sander JW, et al. Incidence of sudden unexpected death in an adult outpatient cohort with epilepsy at a tertiary referral centre. J Neurol Neurosurg Psychiatry 1995;58:462-4.

2 Langan Y, Nolan N, Hutchinson M. The incidence of sudden unexpected death in epilepsy in South Dublin and Wicklow. Seizure 1998:7:355-8

3 Leestma JE, Walczak T, Hughes JR, et al. A prospective study on sudden unexpected death in epilepsy. Ann Neurol 1989;26:195-203.

4 Ficker DM, So EL, Shen WK, et al. Population based incidence of sudden unexplained death in epilepsy. Neurology 1998;51:1270-4.

5 Coyle HP, Baker Brian N, et al. Coroners' autopsy reporting of sudden unexplained death in epilepsy (SUDEP) in the UK. Seizure 1994;3:247-254

6 Nashef L. Sudden unexpected death in epilepsy: incidence, circumstances and mechanisms. MD thesis, University of Bristol, 1995

7 Brown SW, Mawer GE, Lawler W, et al. Sudden death and epilepsy. [Letter]. Lancet 1990;335:606-7.

8 Nashef L. Sudden unexpected death in epilepsy: terminology and definitions. Epilepsia 1997;38:S6-8.

9 Office for National Statistics. Twentieth century mortality files for England and Wales. London: HMSO, 1999.

10 Bell GS, Sander JW. The epidemiology of epilepsy: the size of the problem. Seizure 2001;10:306-14. 